Journal

Journal of Liquid Chromatography \& Related Technologies >

Volume 40, 2017 - Issue 17

470

0

Views CrossRef citations Altmetric

ARTICLES

\title{
Stability-indicating RP-HPLC method for simultaneous quantitation of tramadol and aceclofenac in presence of their major degradation products: Method development and validation
}

Md. Gousuddin, Pinaki Sengupta $\boldsymbol{\nabla}$, Bappaditya Chatterjee \& Sreemoy Kanti Das Pages 887-893 | Accepted author version posted online: 25 Sep 2017, Published online: 25 Sep 2017

G6 Download citation $\boldsymbol{\nabla}$ https://doi.org/10.1080/10826076.2017.1381849

(A) Check for updates

Select Language $\mid \nabla$

Translator disclaimer

\section{ABSTRACT}

Primary objective of this study was to develop a stability-indicating reverse-phase highperformance liquid chromatography (HPLC) method for simultaneous quantitation of tramadol and aceclofenac in presence of their degradation products. The drugs were subjected to various International Conference on Harmonization recommended stress conditions, such as acid hydrolysis, alkaline hydrolysis, peroxide oxidation,

thermolysis, and photolysis. The major degradation products got well resoluted from the analytes in HPLC analysis with a mobile phase composed of a mixture of $0.01 \mathrm{M}$ 


\section{EF Full Article $\square$ Figures \& data $\quad \exists$ References SSCitations 山l Metrics}

The analytes were detected ac a vravercirgth of $270 \mathrm{~nm}$. The method was validated and found to be specific, accurate, precise, stable, and robust for its intended use. The method can be recommended for its future use in routine quality control, accelerated and real-time stability analysis of the formulations containing tramadol and aceclofenac combination.

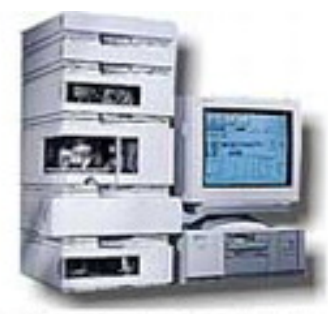

HPLC metbod development for tramadel and aceclofease comblastioa
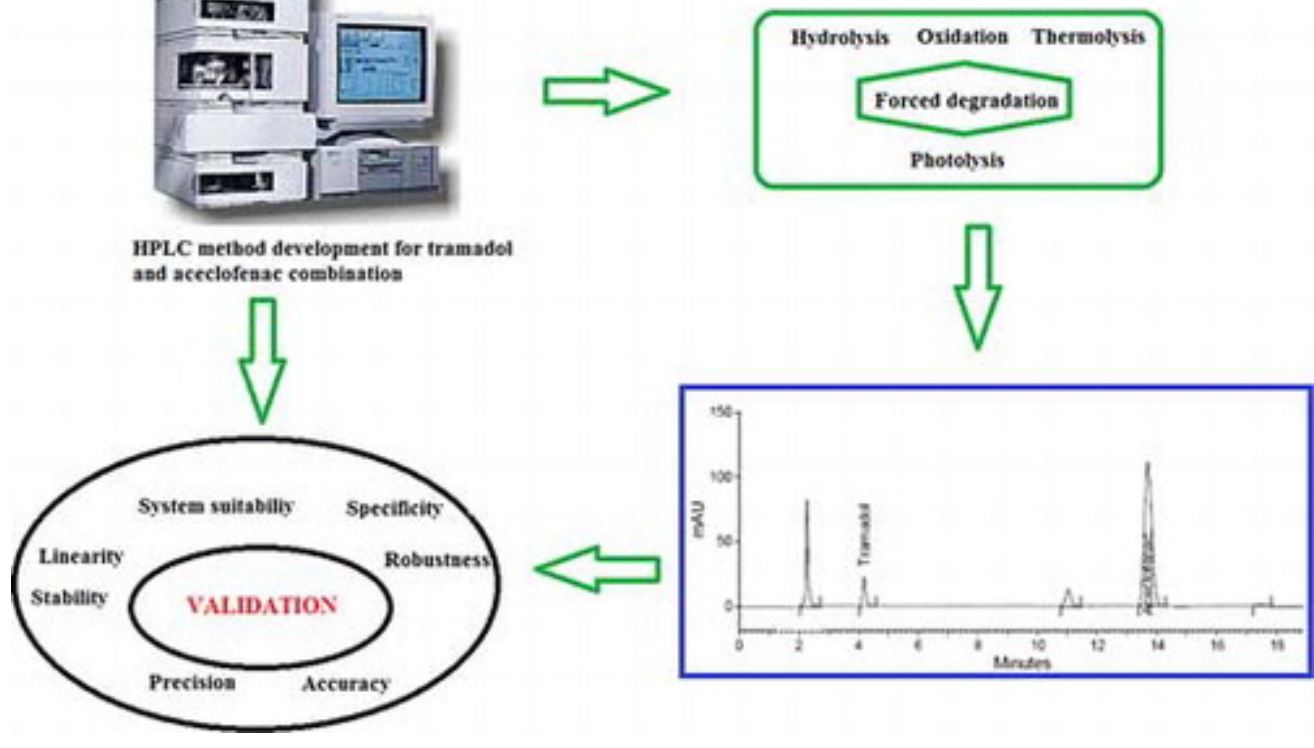

KEYWORDS: Aceclofenac, forced degradation, HPLC, stability-indicating method, tramadol, validation

\section{Additional information}

\section{Funding}

Authors are grateful to Lincoln University College Malaysia and International Islamic University Malaysia for providing the necessary instruments and financial supports to perform this research. 


\section{Log in to Taylor \& Francis Online}

Enter your email

Enter your password

Remember Me

\section{Or purchase it *}

Issue Purchase 30 days access for USD 394.00

\section{Article Purchase 24 hours access for USD 50.00}

* Local tax will be added as applicable

\section{People also read}

\section{Article}


combination dosage form by RPHPLC >

D. Sangeetha et al.

Journal of Liquid Chromatography \& Related

Technologies

Volume 40, 2017 - Issue 11

Published online: 13 Jul 2017

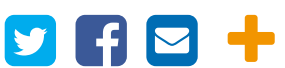

Sample Our

Physical Science journals
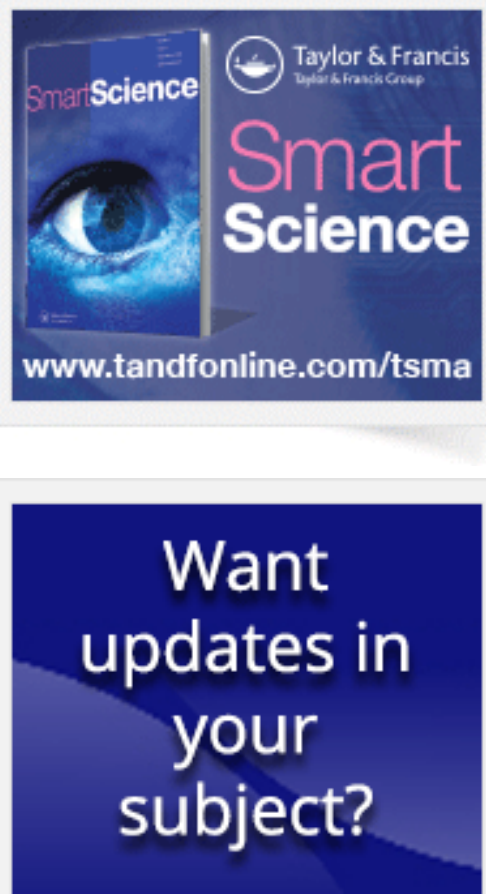


\section{Editors}

Librarians

Societies

Help and info

Help

FAQS

Press releases

Contact us

Commercial services
Open journals

Open Select

Cogent OA
Connect with Taylor \& Francis

\section{$f \nabla$ in

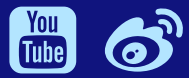

Copyright $\odot 2018$ Informa UK Limited Privacy policy \& cookies Terms \& conditions Accessibility

Registered in England \& Wales No. 3099067

5 Howick Place | London | SW1P 1WG 